at Lerwick and Eskdalemuir, are administered and staffed by the Meteorological Office, the third at Hartland Point (previously at Abinger) by the Royal Greewich Observatory. The staff who have been posted to the Meteorological Office observatories have had to divide their allegiance between the almost unrelated sciences of meteorology and geomagnetism, for no senior post has been attached to the latter. Nevertheless, this association of geomagnetism with the Meteorological Office has been not unsuccessful, for the traditions established by Chree have been well maintained by Goldie, Stagg, and more recently, McIntosh and Lewis. Yet there is surely a strong case for the establishment of at least one senior observatory post so that a man of proved ability in geomagnetic studies, who wishes to devote himself to such work, may do so without sacrificing his prospects of promotion.

The annual report begins with a summary by the Director-General of the changes as they affect the Meteorological Office as a public service and scientific institution. In this, Sir Graham Sutton points out that the advantages of the reorganization will be fully realized only when the staff at present at Victory House, Harrow, Dunstable and the Training School at Stanmore move together to occupy the new buildings, now being erected at Bracknell and likely to be completed in 1961. There follows a detailed account by the Director of Services of the responsibilities of his directorate, which includes not only general forecasting for a wide range of customers, but also the complex organization of communications, the observations, both surface and upper air, on land and at sea, the climatological services, agricultural meteorology and training. The Director of Research summarizes the various problems now under investigation and discusses the work of instrument development, which is also his responsibility. Research on numerical forecasting, involving the development of techniques for predicting the pressure distribution by calculations from the dynamical and physical equations by means of an electronic computer, is being actively pursued. This very readable report concludes with two short chapters on international co-operation and administration.

With the recent rapid development of techniques for the measurement of the physical structure of the atmosphere to great altitudes and their wide use throughout the world during the International Geophysical Year, the mass of new data which is becoming available will make possible the investigation of many fundamental problems in meteorology that were hitherto intractable. The quite excellent facilities for this research which are now provided in the Meteorological Office have therefore been achieved at an opportune time, and it can be confidently anticipated that the national service will play an increasingly important part in advancing the science of meteorology.
J. PATON

\title{
SUPPLY AND DISTRIBUTION OF CHEMICAL ENGINEERS IN BRITAIN
}

$\mathrm{T}$ HE Institution of Chemical Engineers, ever since its inception thirty-five years ago, has pressed for an appreciation of the importance of chemical engineering in the national economy and has made unceasing efforts to promote the training of chemical engineers; but development in Britain lagged far behind that in the United States, and it was not until the beginning of the Second World War, when the University of London was persuaded to institute a degree in chemical engineering, that the profession was generally recognized as a separate discipline. From that time progress was more rapid, and in recent years, following the national awakening to the importance of professional engineers and the multiplication of training courses, the number of chemical engineers has increased still more rapidly. The increase would have been greater still but for one factor, long foreseen by the profession-the evergrowing difficulty of obtaining qualified teachers. A state had been reached in which a promising graduate, immediately on leaving the university, could secure a higher salary in industry than some of those who had taught him. It was consequently not surprising that there were few candidates for teaching posts.

Earlier this year the Institution published a survey of output of chemical engineers in Great Britain, from which it was concluded that by 1966 , provided the situation as regards teaching staff did not become worse, the yearly output might be about 950 , as against a requirement of at least 1,100 (see Nature, 181,1382 ; 1958). This would be an improvement on the present position but would still leave a shortage. Statistical information on this subject is scanty and the Institution has recently circularized its qualified members in order to ascertain where they work, in what industry and what position they hold. Salaries, unfortunately, have been omitted. 79 per cent made returns and it was hoped that these might indicate a special shortage of chemical engineers either in certain regions, industries or occupations. The results are interesting, but difficult to interpret; for example, the number of chemical engineers in a given region depends mainly upon the number of factories of a type employing a high proportion of chemical engineers (for example, oil refineries) which happen to be located in that region. It also depends on the prospects which the new recruit considers that these factories offer and on the amenities of the district. A low figure for any region does not necessarily indicate that many more chemical engineers are required there.

The returns showing the occupation of members are more illuminating, as they can be compared with similar figures for 1953 . In that year, about 20 per cent were engaged in each of four main branches : (1) administration and management; (2) plant operation and maintenance; (3) design and construction; and (4) research and development. In 1957 , no less than 30 per cent were occupied in administration ; a remarkable increase, due, perhaps, to the multiplicity of subjects, not all purely technical, which chemical engineers have to study and the wide outlook which results. This increase is offset by a reduction from $22 \cdot 8$ to $12 \cdot 3$ per cent in the numbers engaged in the operation and maintenance of chemical plant, and is a welcome sign 
since it not only indicates the advancement of automatic control but also a diminution of the employ. ment of graduates in duties which could be carried out equally well by those with lower qualifications. It is surprising to find that corresponding figures for two of these major branches in the United States differ considerably, being 31 per cent for research and development compared with 23 per cent in Britain, but only 7 per cent for design and construction against 21 per cent, a possible explanation being that development may be carried further in the United States and may include much which is classed as design in Britain. Among the minor occupations, teaching shows a gratifying increase from $3 \cdot 0$ to $5 \cdot 1$ per cent, the present number of teachers being more than 100 , but this is still not enough.

The total number of qualified members of the Institution in 1957 was 2,176 , a figure considerably higher than that given in the Government report on Scientific and Engineering Manpower in 1956. The distribution of these members among thirty-three different industries and occupations is shown and also the number of chemical engineers per 1,000 males employed. As might be expected, the mineraloil refining industry, which may be regarded as the cradle of chemical engineering, heads the list with $7 \cdot 3$ chemical engineers per 1,000 employed, and it may also be noted that it was calculated some years ago that the value of the product per manhour in the oil industry was far higher than in any other heavy manufacturing industry. Oil refining seems to be approaching a state in which the only labour required will be for the erection and maintenance of plant, operation being entirely automatic, and its chemical engineers are employed in research, design, development and management. It would, however, be unwise to conclude from this that the efficiency of an industry is directly related to the number of chemical engineers employed. The iron and steel manufacturing industry, in which many chemical engineering processes are involved, employs only twenty chemical engineers, or 0.05 per 1,000 males, and is at the bottom of the list. It is true that automatic operation has not been adopted in this industry to the same extent as in the case of oil, but this is doubtless because it would be more complicated and difficult to install, and would prob. ably be uneconomic. There is certainly no question of the iron and steel industry being inefficient, but there is a possibility that it does not recognize fully the potentialities of the chemical engineer, and that many of the highly qualified staff who are, in effect, doing chemical engineering work were recruited as metallurgists or mechanical engineers. This example may show the difficulty of interpreting employment statistics.

Of the other items in the list of industries, one is deserving of particular attention, namely, atomic energy. This has already secured the services of more than one hundred chemical engineers, and it seems certain that the number required in the near future will be very large.

All the figures now published will have their real value, in the future. It is to be hoped that a similar set will be published in about five years time, and it may then be possible to make reliable predictions. Even now, it may be regarded as a practical certainty that there will be no overproduction of chemical engineers in the coming quinquennium.

H. E. WATSON

\section{FUEL AND POWER IN BRITISH INDUSTRY}

$I^{T}$ $\mathrm{T}$ is abundantly clear that the supply of suitable fuels and the provision of adequate power represent essential factors in any efficient industrial unit. It may well be doubted, however, whether, in view of the ever-increasing complexity of the situation, those responsible for important industrial decisions are always in a position to appreciate thoroughly all the technological and commercial factors involved. It was in the hope of doing something to assist in the planning of such development, so far as the supply of fuel and power is concerned, that the Manchester Joint Research Council arranged a symposium during November 5-7, which was held at the Manchester College of Science and Technology. A very large amount of material has been published on these matters from the technologieal point of view, and it was not the intention of the Council in organizing the symposium to duplicate this, the general theme of the meeting being the interaction between technological advances and their economic consequences.

The meeting was opened by Lord Mills, Minister of Power, who summed up the Government's policy as permitting the consumer to decide from his own experience what is required to meet his own particular needs, coupled with the provision of expert advice, where this is required. It has been estimated that by 1965 the total fuel consumption of the United Kingdom will have risen to about 300 million tons of 'coal-equivalent' 8 year and to 350 million tons by 1975. A marked change in the pattern of the fuel and power used is to be expected; there will prob. ably be a continued switch from the direct use of raw coal to its application in the more refined forms of gas and electricity and an increase in the use of oil, due to the continued expansion of road transport, the re-equipment of the railways, the continuance of recent trends in domestic heating and the change from solid fuel to oil in those industrial and commercial uses where it has special attractions.

This greater refinement means heavy capital investments but offers great savings both in operating and fuel costs, and, in addition, there is a marked reduction in the atmospheric pollution associated with the use of solid fuel.

It is often argued, the Minister said, that the Government should direct the fuel to be used for specific purposes. In reply to this he added: "We should certainly hesitate to adopt such a policy of Government direction on fuel use for two main reasons. In the first place, the detailed policy of control could not really work; there is so much uncertainty regarding the best fuel to employ in particular conditions and, secondly, if there is one thing which central control lacks it is flexibility. A pattern laid down as appropriate at a particular time might quickly become obsolete and uneconomic". It is important, too, in his view, that the importation of oil should be in the crude form, from an increasing variety of sources and processed at refineries in the United Kingdom. 